\title{
Novel amphiphilic folic acid-cholesterol-chitosan micelles for paclitaxel delivery
}

\author{
Li-Chun Cheng ${ }^{1}$, Yan Jiang ${ }^{1}$, Yu Xie ${ }^{1}$, Lu-Lu Qiu ${ }^{1}$, Qing Yang ${ }^{2}$, Hui-Yi Lu ${ }^{1}$ \\ ${ }^{1}$ Department of Pharmacy, The Second Affiliated Hospital of Dalian Medical University, Liaoning, Dalian 116027, China \\ ${ }^{2}$ Department of Anesthesia, Critical Care and Pain Medicine, Massachusetts General Hospital, Boston, MA 02144, USA \\ Correspondence to: Hui-Yi LU, email: $15541117912 @ 163 . c o m$ \\ Qing Yang, email: qhyang@partners.org
}

Keywords: paclitaxel, folate acid, cholesterol, chitosan, micelle

Received: May 23,2016 Accepted: November 21, 2016

Published: December 01, 2016

\section{ABSTRACT}

In order to decrease the toxicity of paclitaxel (PTX) and increase the efficiency, we developed an amphiphilic PTX injection system using a biodegradable and biocompatible polymer synthesized by folic acid, cholesterol, and chitosan (FACC). This FACC-based polymer had a low critical concentration $(64.13 \mu \mathrm{g} / \mathrm{ml})$ and could selfassemble in aqueous condition to form nanoscale micelles. The particle sizes of FACCPTX micelles were $253.2 \pm 0.56 \mathrm{~nm}$, the encapsulation efficiency and loading capacity of these FACC-PTX micelles were $65.1 \pm 0.23 \%$ and $9.1 \pm 0.16 \%$, respectively. The cumulative release rate was about $85 \%$ at $\mathrm{pH} 5.0$ which was higher than that at $\mathbf{p H} 7.4$ (76\%). This $\mathrm{pH}-d e p e n d e n t$ release behavior was highly suggesting that PTX release from FACC-PTX micelles might be higher in a weak acidic tumor microenvironment and lower toxic for normal cells. The anti-cancer effectiveness of FACC-PTX micelles was investigated by in vitro cytotoxicity and targeting study. The results revealed that FACC micelles have non-toxic on cells as evidenced by high cell viability found ( $86 \%$ to $100 \%$ ) in the cells cultured with various concentrations of FACC micelles (1 to 500 $\mu \mathrm{g} / \mathrm{ml}$ ). Targeting study indicated that the cytotoxic efficacy of FACC-PTX micelles was significantly higher than that with Taxol $@$ in the Hela cells (folate receptor-positive cells). These findings indicated that the anticancer efficiency of PTX can be enhanced by adding some cancer cell positive receptor into drug carrier and the FACC micelle was a potential tumor targeting carrier for PXT delivery.

\section{INTRODUCTION}

Paclitaxel (PTX) is an effective and wide spectrum chemotherapeutic agent, which has been successfully used in the clinical treatment of many solid tumors, especially breast and ovarian tumor [1]. However, the poor solubility and high toxicity of PTX limits the medical applications of this drug. In order to realize the targeted delivery of PTX to tumor, many methods have been studied. One of successful medications was a commercial drug named Taxol ${ }^{\circledR}$ formulated with Cremophor EL ${ }^{\circledR}$ (polyethoxylated castor oil) and dehydrated ethanol (50:50 v/v). However, cremophor EL ${ }^{\circledR}$ can induce severe side effects as hypersensitivity, neurotoxicity, and nephrotoxicity [2]. The other studies have largely improved the solubility and side effects of PTX but still remained many limitations. The layer-by-layer assembly of chitosan-PTX liposomes enhanced PTX induced cytotoxicity in human cervical cancer cells as compared to PTX [3]. However, particle flocculation or aggregation was difficult to overcome [4]. Peptide-conjugated biodegradable PTX nanoparticles exhibited significantly stronger antiangiogenic activity than Taxol ${ }^{\circledR}$ on endothelial cells [5]. However, the problems with peptide stability and their short blood half-lives due to peptidase sensitivity would limit the effectiveness of peptide-conjugated drugs. Chitosan-PLGA particles were significantly enhanced PTX cytotoxicity for 4T1 cells [6]. Because carboxylic acid chain ends are the products of the hydrolytic cleavage of PLGA polymers, the degradation of the PLGA polymer may lead to high acidic and painful products locally [7]. Therefore, a less toxic and bettertolerated delivery system for PTX to substitute Taxol ${ }^{\circledR}$ is still a big challenge for both clinical medical doctors and anti-cancer researchers.

Among these new delivery systems, polymeric micelles are recognized as one of the most potential 
chemotherapeutic agent delivery systems, due to their good solubilization efficiency and reducing non-selective reticuloendothelial system (RES) scavenge. Moreover, the nanoscale dimension polymeric micelles exhibit tumor accumulation by enhancing permeability and retention (EPR) effect [8]. Chitosan is widely distributed in nature and used in micelle system owing to its good physicochemical characters, including biodegradability, biocompatibility, low toxicity, $\mathrm{pH}$ sensitiveness and ease of chemical modification [9]. However, chitosan suffers from a poor solubility in water, which is a major drawback for drug formulations [10]. In order to improve the properties of chitosan, chemical modification of the chitosan chains has been investigated. Amphiphilic copolymers present a double affinity for both hydrophilic and hydrophobic environments and are able to self-organize in water to form, in most cases, specific architectures such as micelles or vesicles [11].

In recent years, several chitosan PTX micelle were studied, such as N-succinyl-palmitoyl-chitosan PTX micelles [12], N-octyl-N-(2-carboxylbenzoyl) chitosan PTX micelles [13], amphiphilic carboxymethyl chitosanquercetin PTX micelles [14] and $\alpha$-tocopherol succinatemodified chitosan PTX micelles [15]. However, their applications are greatly limited due to high toxicity on normal cells. In order to enhance the tumor targeting of micelles system and decrease the injury to normal tissues, a new modified PTX delivery system is needed. Folic acid (FA) and its derivatives are essential nutrients in humans and play an important role in nucleotide synthesis and methylation reactions. Our hypothesis is that PTX can be delivered effectively by a chitosan modified with folic acid system, which is higher expression in human cancer cells such as Hela and KB cells than in normal cells $[16,17]$.

The aim of this study is to test our hypothesis by developing a novel amphiphilic folic acid-cholesterolchitosan-conjugated PTX micelle system to target folate receptor positive cancer cells. Folic acid-cholesterolchitosan (FACC) is synthesized by aminoacylation reaction of chitosan primary amino groups and FACC-PTX micelles are prepared by dialysis method. Subsequently, the physical properties and biological activity of FACCPTX micelles are characterized. In addition, cancer targeting specificity of FACC-PTX micelles is determine using Hela (folate receptor-positive) and A549 (folate receptor-negative) cells [16].

\section{RESULTS}

\section{Synthesis and characterization of CH-CS and FACC}

In order to develop a novel PTX delivery system, we synthesized a chitosan-based new polymer using folic acid (FA), cholesterol (CH) and chitosan (CS) as described in the scheme (Figure 1). FT-IR spectrum has indicated that a FACC polymer has been synthesized by three-step reactions. At the first step, the hydroxyl group of cholesterol was activated by succinic anhydride to form cholesterol succinate. At the second step, cholesterol succinate reacted with chitosan to create a cholesterolchitosan (CH-CS) polymer. At the third step, FA reacted with $\mathrm{CH}-\mathrm{CS}$ polymer to form a FACC polymer. As shown in Figure 2A, the basic characteristics of FT-IR bands of chitosan at $3468 \mathrm{~cm}^{-1}$ was assigned to the stretching vibration of $\mathrm{O}-\mathrm{H}$ and $\mathrm{N}-\mathrm{H}$. This peak was still expressed in the FT-IR spectrum of CH-CS polymer (Figure 2B). However, new peak appeared at approximately 1652-1940 $\mathrm{cm}^{-1}$ which were attributed to the formation of -NHCOgroup in CH-CS (Figure 2B) and FACC (Figure 2C) polymers. The appearance of the peak at $1709 \mathrm{~cm}^{-1}$ in the spectrum was attributed to benzene ring of the FA, which stand for amide linkage was identified in FA modified $\mathrm{CH}$ CS (Figure 2C).

${ }^{1} \mathrm{H}$ NMR was investigated to further confirm the chemical structure of the CH-CS and FACC. The characteristic peaks of chitosan (Figure 3A) appeared at 1.0-3.0 ppm. Compared with chitosan and $\mathrm{CH}-\mathrm{CS}$, new peaks in $\mathrm{CH}-\mathrm{CS}$ spectrum (Figure 3B) appeared in the range of 3.5-5.5 ppm due to the hydrogen protons of cholesterol moiety, which suggested that cholesterol modified groups were successfully grafted onto the chitosan backbone.

Compared the ${ }^{1} \mathrm{H}$ NMR spectrum of FACC (Figure $3 \mathrm{C}$ ) and $\mathrm{CH}-\mathrm{CS}$ (Figure 3B), the ${ }^{1} \mathrm{H}$ NMR $\delta$ spectrum of FACC exhibited the new peaks at 2.5 (br s, $\beta$ and $\gamma$-CH2groups, $4 \mathrm{H}), 5.95 \mathrm{ppm}$ (s, aromatic $\mathrm{H}$ of pteridine) and $6.65 \mathrm{ppm}$ (benzene ring) as shown in Figure 3. The appearance of these peaks confirmed the successful conjugation of folate with $\mathrm{CH}-\mathrm{CS}$.

\section{Critical micelle concentration (CMC)}

The CMC of the FACC was determined by pyrene fluorescence probe technique. At low concentration (C) of FACC $(\mathrm{C}<\mathrm{CMC})$, there were negligible changes in fluorescence intensity ratio of I384/I372. As the concentration increased, remarkable increase of the intensity ratio was observed by fluorescence spectroscopy. The CMC curves of FACC determined from emission spectra of pyrene in FACC solutions were shown in Figure 4 . Based on the intensity ratio data, the $\mathrm{CMC}$ value of FACC was calculated by the crossover point. The CMC value of FACC was $64.13 \mu \mathrm{g} / \mathrm{ml}$, which demonstrated that FACC could form very stable micelles at low concentration.

\section{Physicochemical characterization of PTX-FACC micelles}

Dialysis method was used to prepare FACC micelles and PTX-FACC micelles. The encapsulation efficiency 
(EE), loading efficiency (LE), mean diameter size and polydispersities (PDI) of PTX-FACC micelles were shown in Table 1 with the different dialysis times. The result demonstrated that $\mathrm{EE}, \mathrm{LE}$ and the micelles size of the micelles were decreased with the dialysis time extension. The PTX-FACC micelles (dialysis time $8 \mathrm{hrs}$ ) were both have high EE and LE, but with low particle size, were selected for future research. The morphology of PTX-FACC micelles were determined by TEM (Figure 5). FACC micelles and PTX-FACC micelles had uniform spherical morphology, and the distribution of particle size was in the range of 100-250 $\mathrm{nm}$. These results were in agreement with the measurement of Zetasizer Nano ZS90 instrument (Figure 6).

\section{In vitro release of $\mathrm{PTX}$ from $\mathrm{PTX}-\mathrm{FACC}$ micelles}

The concentration of PTX released from PTXFACC micelles was determined in vitro at $37^{\circ} \mathrm{C}$ in $\mathrm{PBS}$ solution with 3 different $\mathrm{pH}(5.0,7.4,9.0)$ conditions. The PTX released from commercial drug, Taxol was also tested at the same conditions $(\mathrm{pH} 7.4)$ and used as a control (PTX group). Our results showed that the releasing process of PTX was faster at acidic condition $(\mathrm{pH}=5.0)$ than both physiological condition $(\mathrm{pH}=7.4)$ and basic condition $(\mathrm{pH}=9.0)$ from FACC-PTX micelles (Figure 7). PTX released from commercial drug, Taxol (PTX group) was much faster than that from FACC-PTX micelles. More than $95 \%$ of PTX released from Taxol $\AA$<smiles>CC(C)CCCC(C)C1CCC2C3CC=C4CC(O)CCC4(C)C3CCC12C</smiles>

Cholesterol (CH)

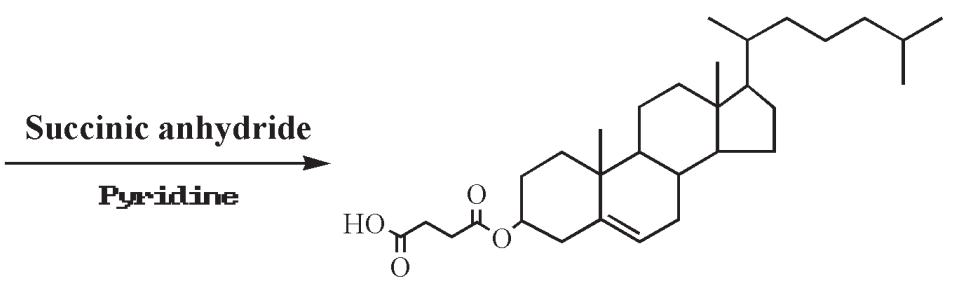

Cholesterol Succinate

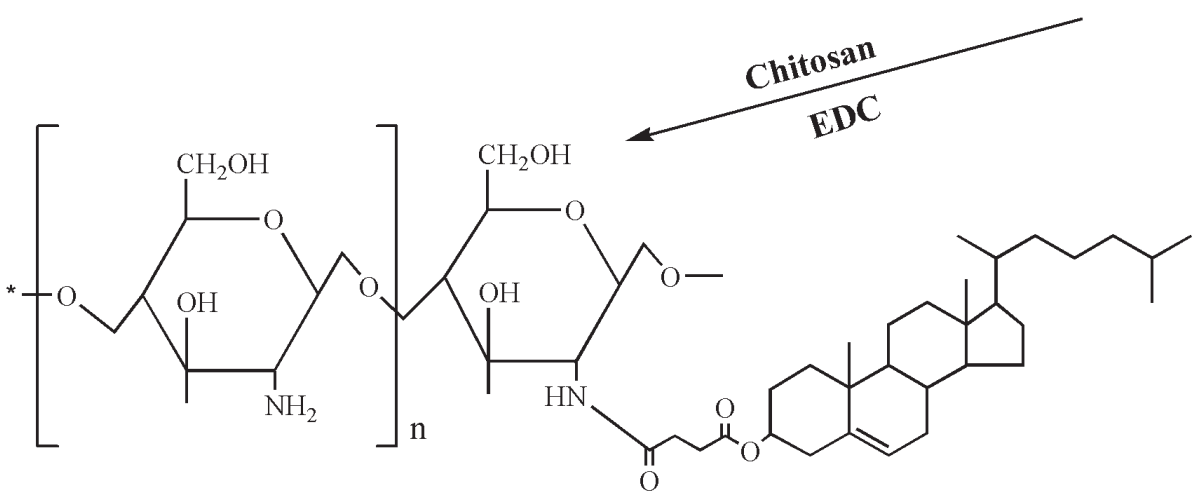

Cholesterol Chitosan (CH-CS)
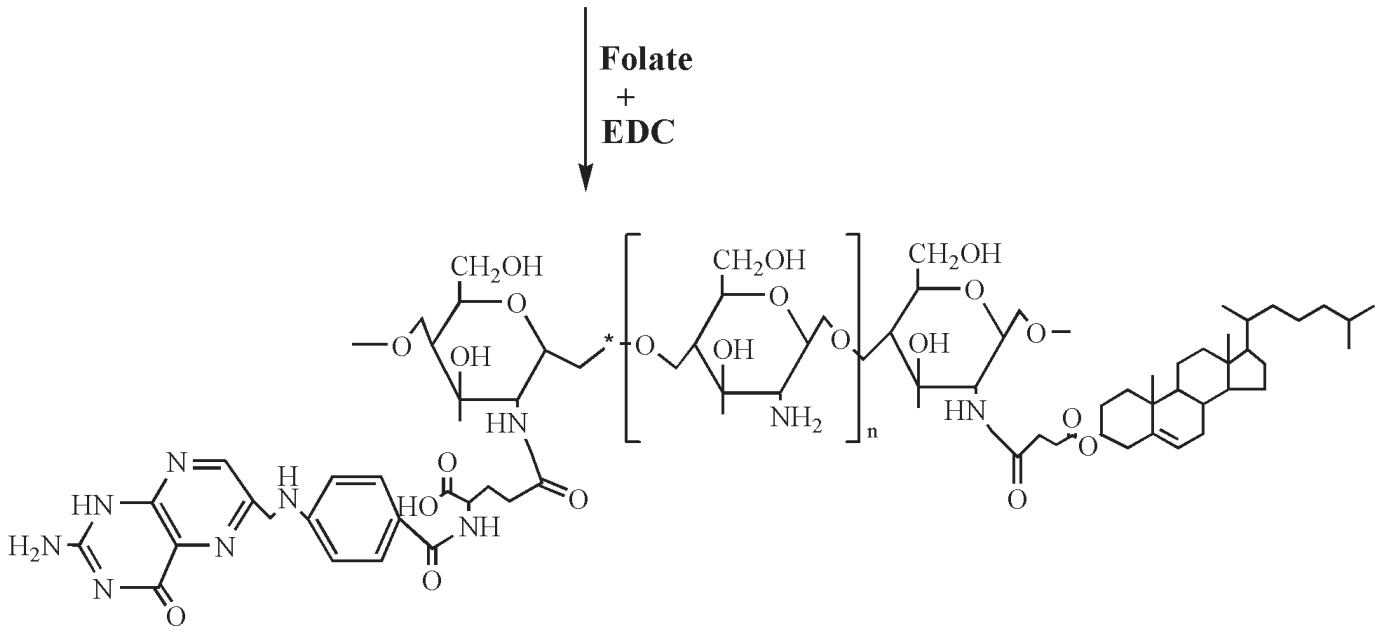

Folate Cholesterol Chitosan (FACC)

Figure 1: Schematic representation of the synthesis of FACC from cholesterol, chitosan and folate. 
at pH 7.4 in 24 hours (Figure 7). However, FACC-PTX micelles released the same levels of PTX at the end of 96 hours. As presented in Figure 7, about 92\% of PTX was released within 96 hours at $\mathrm{pH} 5.0$, while about $86 \%$ of PTX was released at $\mathrm{pH}$ 7.4. This $\mathrm{pH}$-dependent release behavior was highly suggesting that PTX release from FACC-PTX micelles might be higher in a weak acidic tumor microenvironment [18] and lower toxic for normal cells.

\section{In vitro cytotoxicity}

Cytotoxicity of the FACC-PTX micelles was evaluated using MTT assay on Hela and A549 cells and

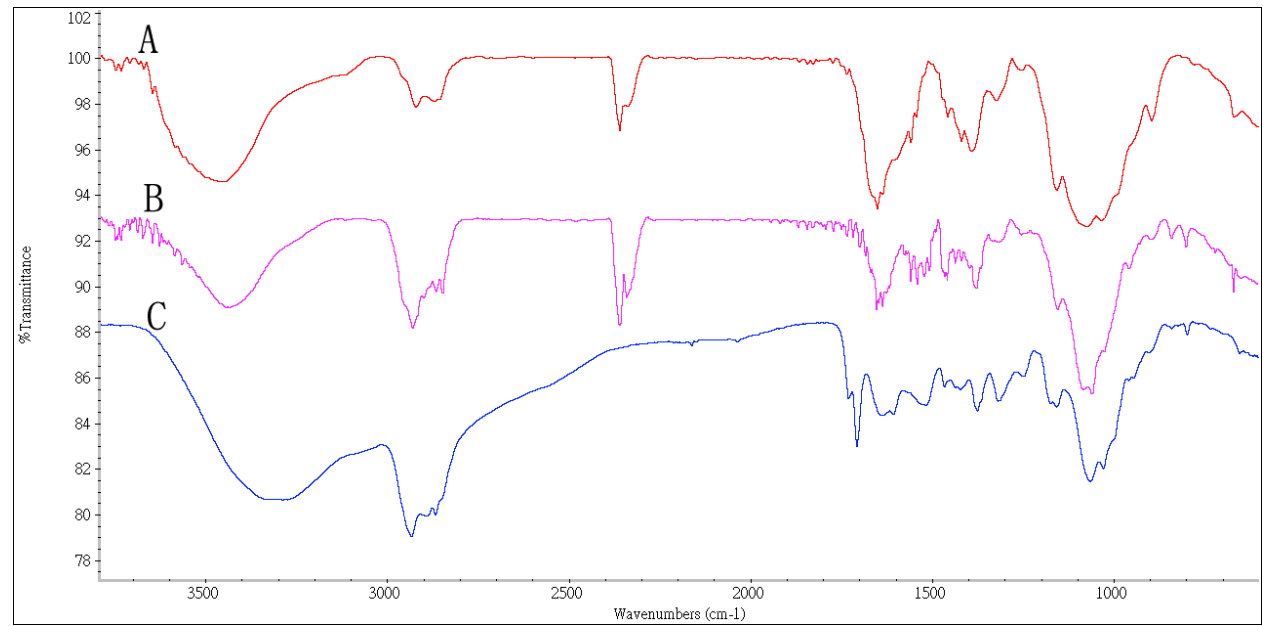

Figure 2: FTIR Spectra of chitosan exhibiting absorbance of $-\mathrm{OH}$ and $-\mathrm{NH}$ groups at $3468 \mathrm{~cm}^{-1} \mathrm{~A}$. , synthesized cholesterol-chitosan (CH-CS) polymer at $1652 \mathrm{~cm}^{-1}(\mathrm{C}=\mathrm{O}$ stretch overlapped with $\mathrm{N}-\mathrm{H}$ bend; B., and folate-cholesterolchitosan (FACC) polymer at $1709 \mathrm{~cm}^{-1}$ (benzene ring; red line: FACC; blue line: CS; C., respectively.

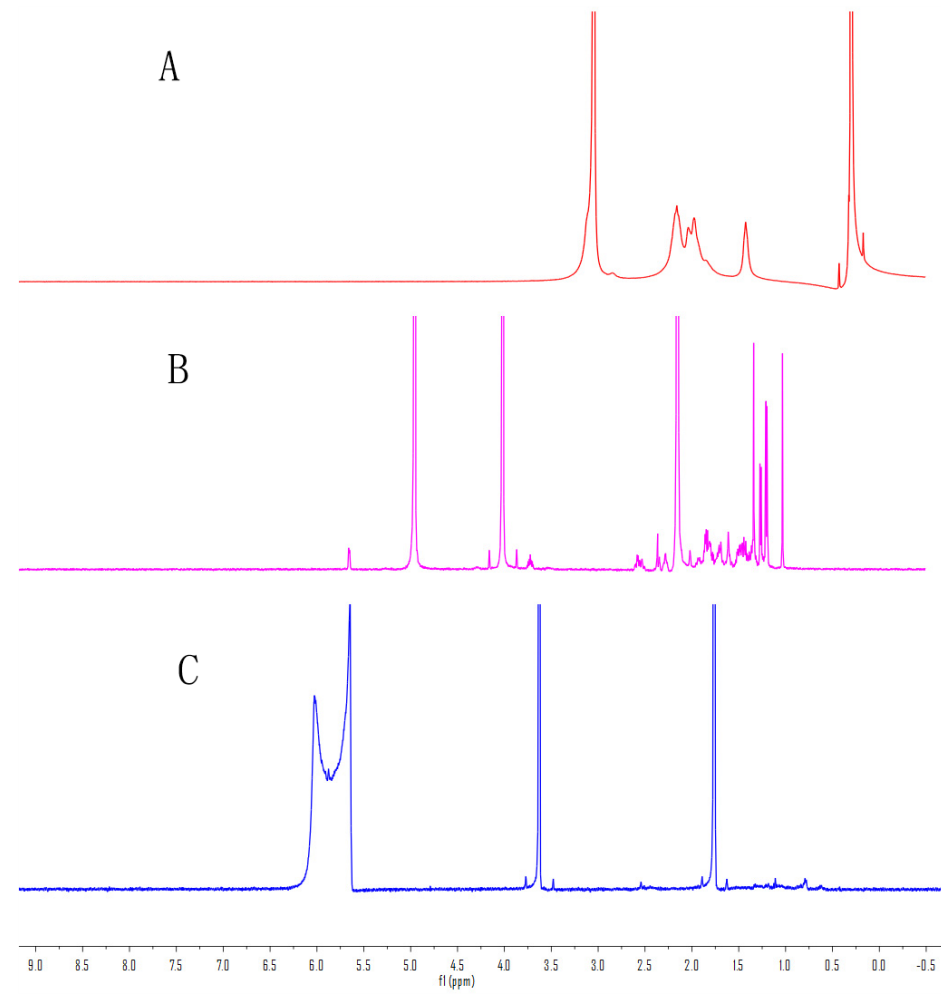

Figure 3: ${ }^{1} \mathrm{H}$ NMR spectra demonstrating the structure of chitosan A., cholesterol-chitosan B., and folate-cholesterolchitosan $\mathbf{C}$. 
directly compared their efficacies to that of Taxol®. FACC micelles did not have any obvious effect on the Hela and A549 cells throughout the whole range of concentrations examined (Figure 8). The MTT analyses demonstrated that FACC-PTX micelles were more cytotoxicity than Taxol ${ }^{\circledR}$ (Figure 9). In Hela cells (folate receptor-positive), the cytotoxic efficacy of FACC-PTX micelles was significantly higher than that with Taxol®. However, there was no significantly different cytotoxic efficacy in A549 (folate receptor-negative) cells between FACC-PTX micelles and Taxol ${ }^{\circledR}$. Besides, in the FACC-PTX micelles groups, the cytotoxicity of Hela cells was significantly higher than that with A549 cells (Figure 9). These results were in accordance with those observed in the FACC-PTX micelles cellular uptake.

\section{Intracellular uptake of FITC-FACC micelles}

The intracellular uptake efficiency of FITC in Hela cells and A549 cells was investigated using laser confocal microscope. To precisely observe the cellular distributions of FACC micelles, we performed double fluorescence which with green fluorescence from FITC-FACC micelles and red fluorescence from TRITC-folate receptor. The cells were also counterstained with Hoechst 33342 (blue fluorescence) to form treble fluorescence. As shown in Figure 10, mouch higher fluorescence intensity of FITC was found in Hela cells treated with FITC-FACC micelles than that ofHela cells treated with FITC solution and A549 cells treated with FITC-FACC micelles. However, the fluorescence signal neither found in Hela cells nor in A549 cells when they were treated with FITC solution. The fluorescence intensity of TRITC in Hela cells was found to be higher than that in A549 cells, indicating that the Hela cells have express more folate receptor than A549 cells. This observation suggests that the FACC micelles facilitated intracellular uptake of FITC in the positive folate receptor cells.

\section{DISCUSSION}

Nowadays, amphiphilic micelles have been extensively exploited to improve the therapeutic efficiency and reduce severe side effects of anticancer drugs. Chitosan has been chosen as the micelles carrier material because it has many amino groups on the molecular chain and modified easily [19]. Cholesterolmodified O-carboxymethyl chitosan conjugate is amphiphilic in nature and has self-aggregation behavior in aqueous media [20]. Furthermore, chitosan modified with special materials such as folate [21] and RGD [22] polypeptides constitutes active receptor enhanced targeted drug delivery systems. FA is a stable, inexpensive and poorly immunogenic chemical with a high affinity for the FA receptor [23]. Therefore, in this study, FACC was synthesized to enhance the specificity of PTX delivery to tumor cells/tissues.

To prepare low toxic and higher efficacy FACCPTX micelles, all organic solvents have been removed by dialysis method. Amphiphilic FACC could form to micelles by self-assembly, it was easy to carry hydrophobic anticancer drugs. Folic acid conjugated glycol chitosan micelles for targeted delivery of doxorubicin (DFCHGC) were prepared by emulsion/ solvent evaporation method which induced organic solvent $\mathrm{ClCH}_{3}$. The size of DFCHGC micelles was from 282 to $320 \mathrm{~nm}$, which was larger than FACC-PTX micelles (150$250 \mathrm{~nm})$ [24]. Hydrotropic oligomer-conjugated glycol

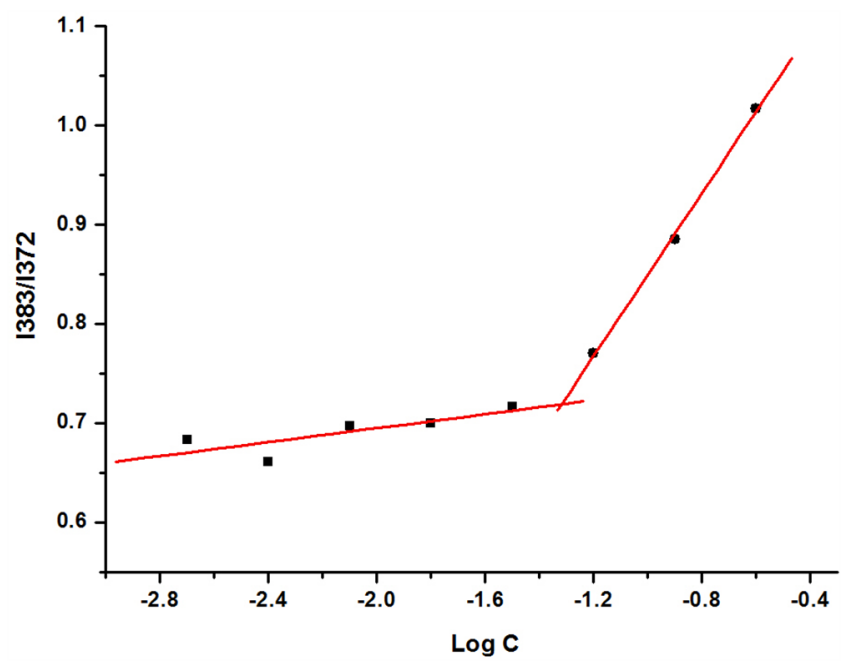

Figure 4: The intensity ratio ((I384/I372) of the pyrene emission spectra versus the log concentrations of FACC. The CMC value of FACC was $64.13 \mu \mathrm{g} / \mathrm{ml}$ calculated by the crossover point, which demonstrated that FACC could form very stable micelles at low concentration. 
Table 1: Physicochemical characterization of PTX-FACC micelles atdifferent dialysis time points $(n=3)$

\begin{tabular}{lcccc}
\hline Dialysis time (h) & LE\% & EE\% & Size (nm) & PDI \\
\hline 4 & $12.93 \pm 0.67$ & $75.57 \pm 2.14$ & $288.5 \pm 4.78$ & $0.217 \pm 0.073$ \\
8 & $10.52 \pm 1.03$ & $63.13 \pm 3.56$ & $266.0 \pm 1.91$ & $0.107 \pm 0.069$ \\
12 & $7.42 \pm 0.87$ & $56.50 \pm 1.96$ & $253.2 \pm 5.10$ & $0.136 \pm 0.056$ \\
24 & $5.45 \pm 0.62$ & $32.73 \pm 0.98$ & $168.8 \pm 1.036$ & $0.185 \pm 0.043$ \\
\hline
\end{tabular}
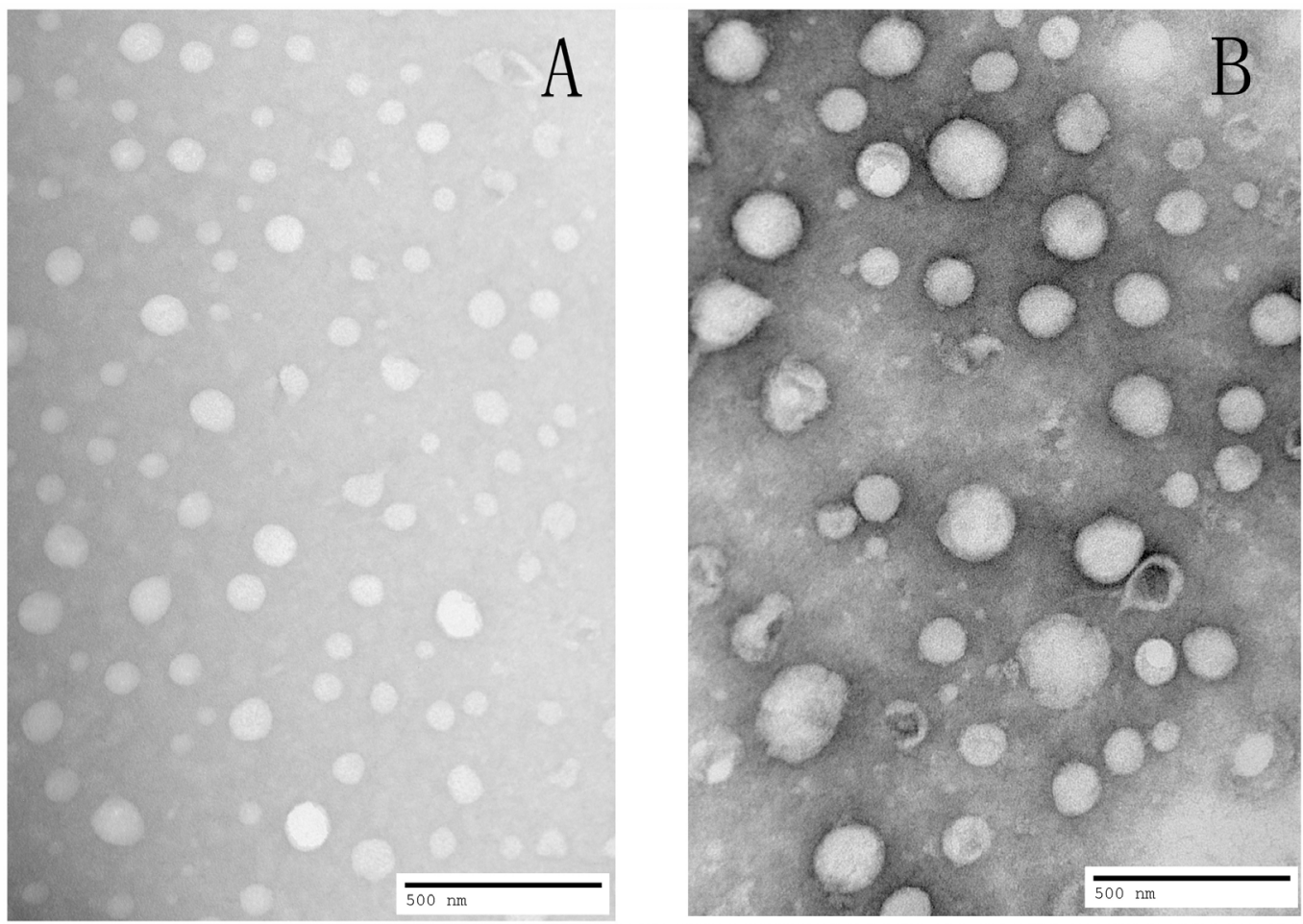

Figure 5: TEM image showing uniform spherical morphology with particle size about 100nm for FACC micelles A. and about 200nm for PTX-FACC micelles B.

\begin{tabular}{|c|c|c|c|c|c|}
\hline & & & Size (d.nm): & $\%$ Intensity & Width (d.nm): \\
\hline Z-Average (d.nm): & 253.2 & Peak 1: & 268.2 & 100.0 & 64.99 \\
\hline Pdl: & 0.049 & Peak 2: & 0.000 & 0.0 & 0.000 \\
\hline Intercept: & 0.911 & Peak 3: & 0.000 & 0.0 & 0.000 \\
\hline
\end{tabular}

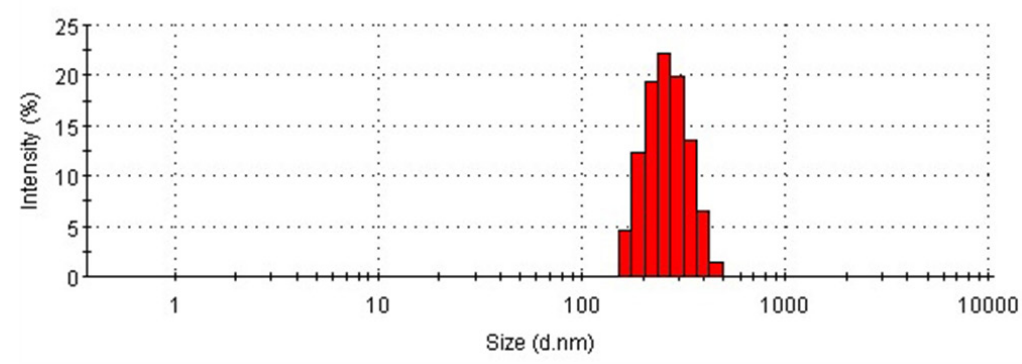

Figure 6: The size distribution of PTX-FACC micelles was in the range of 150-250 $\mathrm{nm}$ determined by Zetasizer Nano ZS90 instrument. 
chitosan paclitaxel nanoparticles (PTX-HO-CNPs) were prepared by dialysis method with the average size 343 $\mathrm{nm}$, which was also larger than FACC-PTX micelles [2]. Although the loading efficiency of PTX-HO-CNPs were about $96 \%$ higher than FACC-PTX micelles (75\%), the smaller size of FACC-PTX micelles would batter for tumor targeting by EPR effect.

The FACC has amphiphilic character, which CMC value was $64.13 \mu \mathrm{g} / \mathrm{ml}$. The higher the degree of substitution of chitosan, the lower the CMC value. The CMCs of N-octyl-N-(2-carboxylbenzoyl) chitosan PTX micelles were from 11 to $72 \mu \mathrm{g} / \mathrm{ml}$ [25]. Cholesterol and folate in the chitosan may have steric hindrance, the degree of substitution of FACC is difficult to be higher.
However, our result showed that FACC could form very stable micelles at low concentration.

The result of FACC-PTX micelles in vitro release suggested that PTX release rate increased with the decreasing $\mathrm{pH}$ value. This result may be attributed to the changes in the structure of the amino of the micelles. In acidic conditions, $-\mathrm{NH}_{2}$ in the surface of micelles transformed to $-\mathrm{NH}_{3}{ }^{+}$through binding protons. The transition between hydrophilic and hydrophobic groups make micelles unstable under acidic solutions [26]. This $\mathrm{pH}$-dependent release behavior was highly desirable for targeted cancer therapy because it could accelerate the amount of drug released at tumor site and decrease the drug release in normal tissues based on the different acid

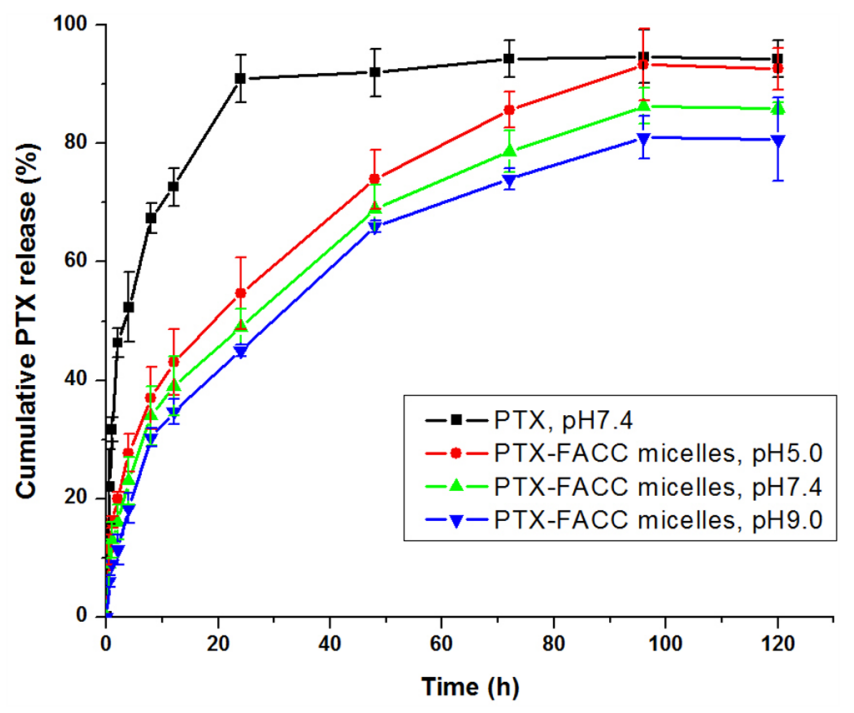

Figure 7: Cumulative release curve of PTX in PBS with 1\% polysorbate 80 at different pH conditions. Data were given as $\operatorname{mean} \pm \mathrm{SD}(\mathrm{n}=3)$.

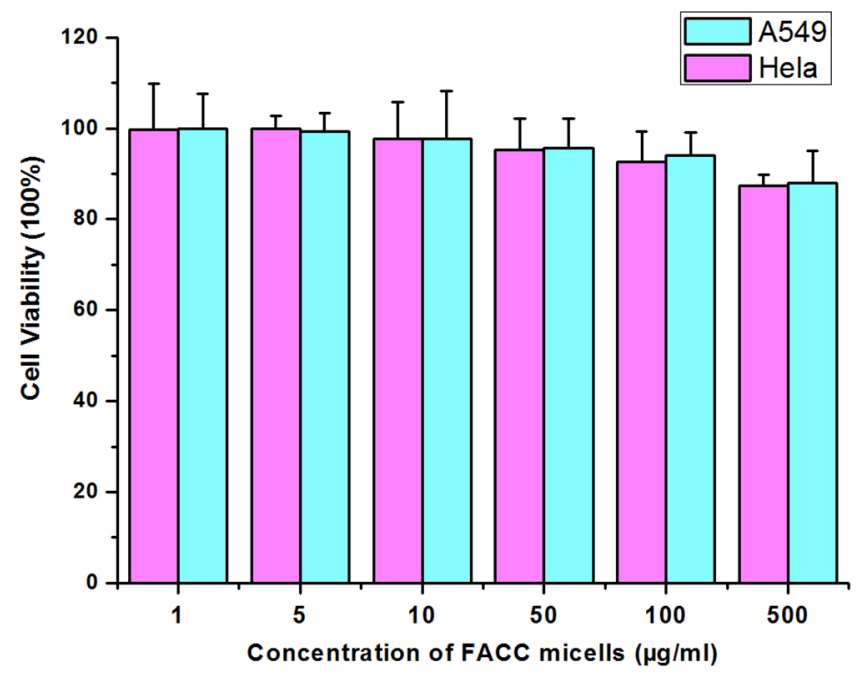

Figure 8: Cytotoxicity of FACC micelles on Hela and A549 cells determined by MTT method. As indicated, FACC micelles have non-cytotoxic effect on Hela and A549 cells. 


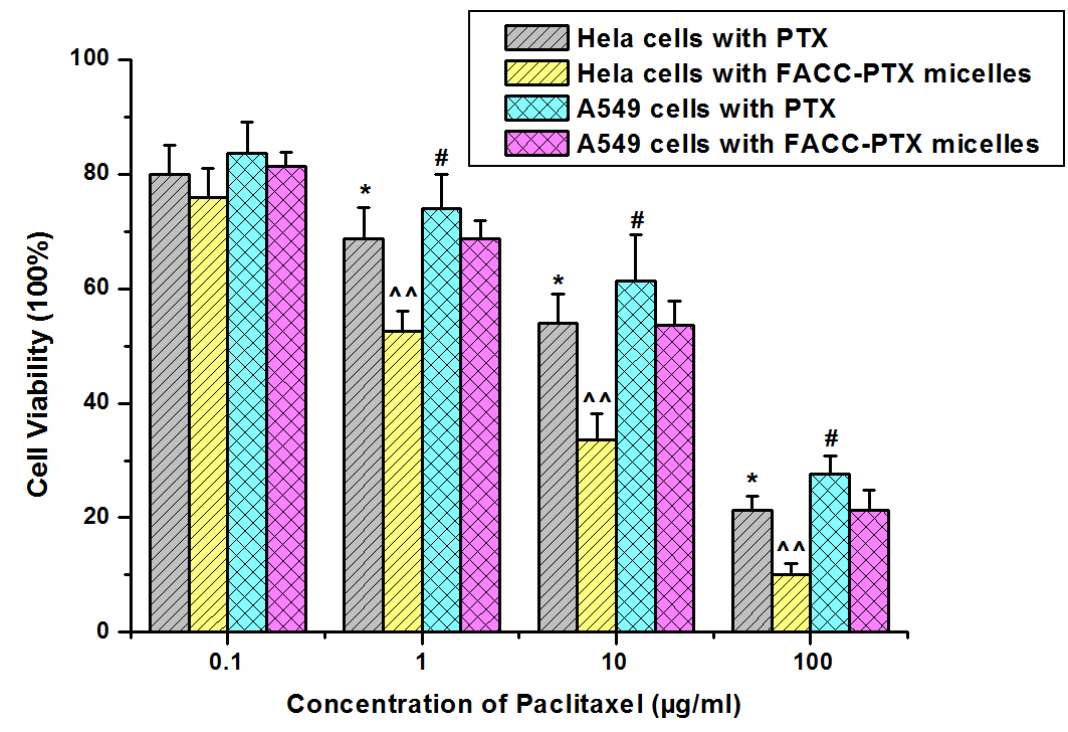

Figure 9: Cytotoxicity of PTX-FACC micelles on Hela and A549 cells determined by MTT method. As presented, significantly higher percentages of Hela cells were killed in PTX-FACC micelles-containing medium (PTX-FACC group) compared to those culture with Taxol-containing medium (PTX group) at the same PTX concentrations $(* P<0.05)$. In addition, PTX-FACC had more targeting effect on Hela cells than A549 cells as evidenced by much lower percentages of Hela cells survived than A549 cells in PTX-FACC micelles-containing medium $(\wedge \wedge P<0.01)$. However, there were no significant differences between Taxol-treated A549 cells and PTXFACC-treated A549 cells ( $\# P>0.05)$. Data are presented as mean $\pm \operatorname{SD}(n=3)$.

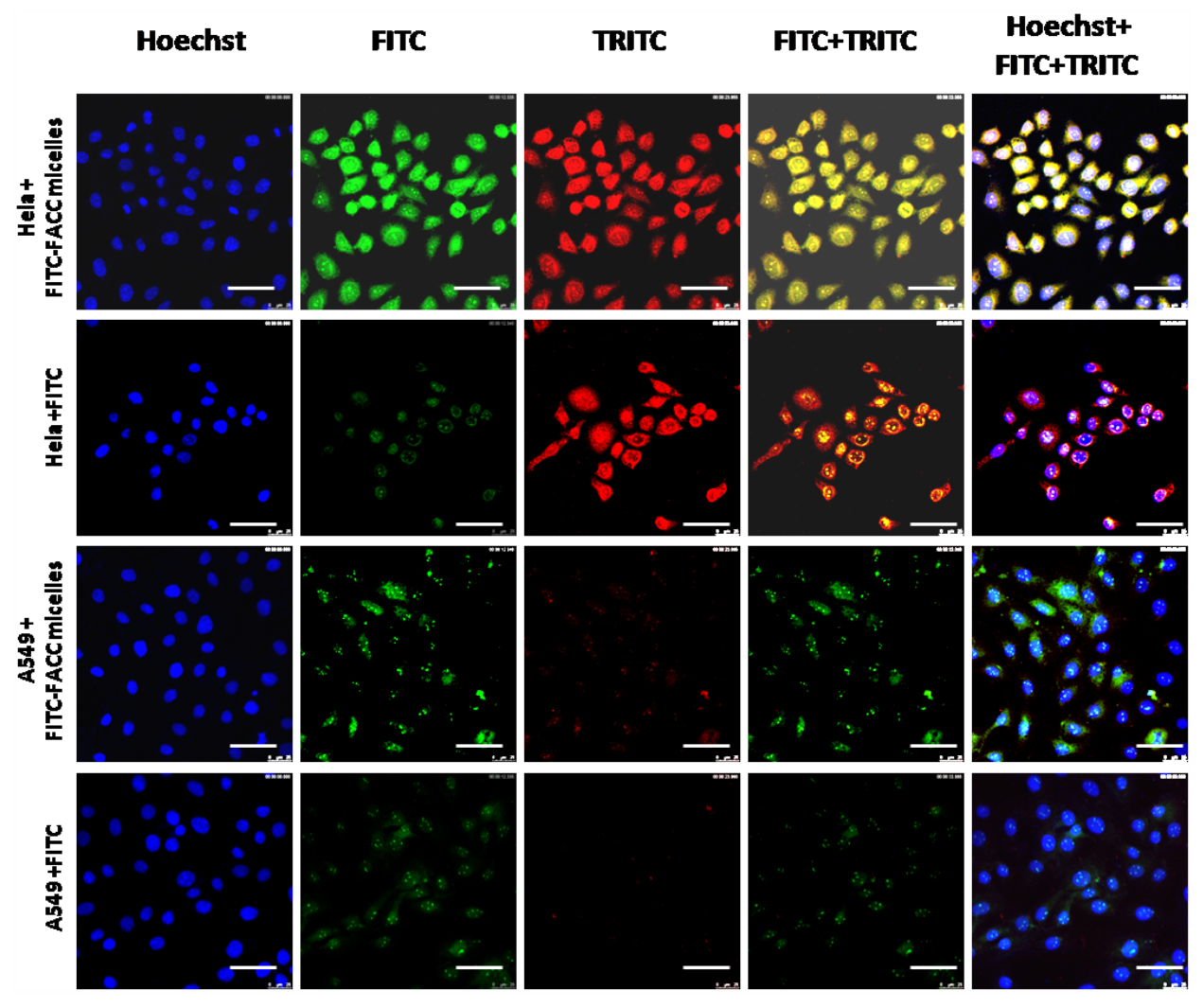

Figure 10: Cellular distribution of FACC micelles in Hela cells and A549 cell for 4 hours, bar=50 $\boldsymbol{\mu m}$. Blue fluorescence from Hoechst labeling the nucleus; green fluorescence from FITC-FACC micelles; red fluorescence from TRITC labeling folate receptor; double fluorescence with FITC and TRITC; treble fluorescence FITC, TRITC and Hoechst. Fluorescence microscope showed that very strong fluorescence signal in FITC-conjugated FACC-PTX treated Hela cells. However, very weak fluorescence signal was found in FITCconjugated FACC-PTX treated A549 cells. There was no fluorescence signal found in Hela cells and A549 cells treated with FITC solution. 
environment between tumor tissues and normal tissues [27].

Cell viability profile assessed by MTT assay demonstrated that FACC micelles had no significant cytotoxicity at concentration as high as $500 \mu \mathrm{g} / \mathrm{ml}$, so that FACC micelles may be a safety tool which possibly overcomes anticancer therapy. We also demonstrated that FACC-PTX micelles targeted Hela cells, the cytotoxic efficacy was significant higher than that with A549 cells. Our results indicate that FACC-PTX micelles were a promising nanoscale drug formulation for cancer therapy.

\section{MATERIALS AND METHODS}

\section{Materials}

Paclitaxel (PTX) was purchased from HaiZheng Co. Ltd. (Zhejiang, China); Chitosan (MW 50 $\mathrm{kDa}$, degree of deacetylation $>90 \%$ ), cholesterol, folic acid (FA), 1-(3-dimethylaminoproply)-3ethylcarbodiimide hydrochloride (EDC), fluorescein isothiocyanate (FITC), phosphate buffered saline (PBS, $\quad$ HH7.4), 3-[4,5-dimethylthiazol-2-yl]-2,5diphenyltetrazoliumbromide (MTT) and dimethylsulfoxide (DMSO) were purchased from Sigma (St Louise, MO, USA). All solvents and reagents used in this study were analytical grade.

\section{Cell lines}

Human cervices carcinoma cell line (Hela), and human lung adenocarcinoma cell line (A549) were purchased from Blood Research Administration (Tianjin, China). The cells were cultured in Dulbecco Modified Eagle's medium (DMEM) supplemented with 10\% fetal bovine serum (FBS), $100 \mathrm{U} \cdot \mathrm{mL}^{-1}$ penicillin and 100 $\mu \mathrm{g} \cdot \mathrm{mL}^{-1}$ of streptomycin at $37^{\circ} \mathrm{C}$ with $5 \% \mathrm{CO}_{2}$.

\section{Synthesis of cholesterol chitosan (CH-CS)}

Cholesterol (0.5 g) and succinic anhydride (0.5 g) were dissolved in $10 \mathrm{ml}$ pyridine. The mixture was stirred for $3 \mathrm{~h}$ at $70^{\circ} \mathrm{C}$ and then the solvents were evaporated with vacuum distillation. The precipitate in the reaction mixture was washed three times with ethanol. The white powder of cholesterol succinate was obtained by recrystallization in ethanol. Subsequently, cholesterol succinate $(100 \mathrm{mg})$ was dissolved in $5 \mathrm{ml}$ methanol and activated by addition EDC $(50 \mathrm{mg})$ under stirring for $1 \mathrm{~h}$. Then $500 \mathrm{mg}$ chitosan in $50 \mathrm{ml}$ of $1 \%$ hydrochloric acid ( $\mathrm{pH} 4.0)$ was added to the above mixture and the reaction was continued for $24 \mathrm{~h}$ at $25^{\circ} \mathrm{C}$. The resultant mixture was dialyzed against distilled water for 3 days using a dialysis bag (cut-off MWCO 7 $\mathrm{kDa}$ ). The synthesized product of cholesterol-chitosan (CH-CS) with the molecular weight bigger than $7 \mathrm{kDa}$ was obtained by lyophilization.

\section{Synthesis of folic acid-cholesterol-chitosan (FACC)}

FACC was prepared through aminoacylation reaction (Figure 1). Briefly, $50 \mathrm{mg}$ FA were dissolved in $10 \mathrm{ml}$ anhydrous DMSO with stirring. EDC (3 mM) was added into the solution and stirred at room temperature for $1 \mathrm{~h}$. Then $25 \mathrm{mg} \mathrm{CH}-\mathrm{CS}$ was dissolved in $25 \mathrm{ml}$ of $\mathrm{HCl}$-THF $(1 \% \mathrm{HCl}$-water : $\mathrm{THF}=1 / 1, \mathrm{v} / \mathrm{v})$ in a new flask to make a clear solution which was added to the FA-DMSO-EDC reaction mixture, stirred at $30^{\circ} \mathrm{C}$ in the dark overnight. The resultant mixture was dialyzed against $0.1 \mathrm{M}$ sodium phosphate buffer ( $\mathrm{pH} 7.4$ ), and changed PBS buffer every two hours for 3 days, followed by dialysis against water and changed water every 6 hours for 3 days using a dialysis bag (cut-off MWCO $7 \mathrm{KDa}$ ). The synthesized product of folic acid-cholesterol-chitosan (FACC) was obtained by lyophilization.

\section{Characterization of FACC conjugates}

The structure of chitosan, $\mathrm{CH}-\mathrm{CS}$ and FACC was analyzed by Fourier transform infrared (FTIR) spectroscopy (WGH-30, Gang Dong Technology Co. Ltd., Tianjin, China) and ${ }^{1} \mathrm{H}$ NMR spectrum (in $\mathrm{D}_{2} \mathrm{O}, 500$ $\mathrm{MHz}$, Bruker spectrometer, Switzerland). For IR spectrum analysis, about $5 \mathrm{mg}$ of dried chitosan, or CH-CS or FACC sample was mixed with $50 \mathrm{mg}$ of $\mathrm{KBr}$ and grounded with pestle and mortar to make thin discs, respectively. The spectra were scanned at room temperature from 400 to $4000 \mathrm{~cm}^{-1}$ wavelength with a resolution of $2 \mathrm{~cm}^{-1}$. For ${ }^{1} \mathrm{H}$ NMR analysis, chitosan, CH-CS, and FACC were dissolved in deuterated reagents and confirmed by ${ }^{1} \mathrm{H}$ NMR spectrometer.

\section{Critical micelle concentration (CMC)}

The CMC of the FACC was determined by using pyrene $(>95 \%$, Sigma, St Louise, MO, USA) as a hydrophobic probe in fluorescence spectroscopy (Perkin Elmer, IS55, USA). The pyrene solutions $\left(6.0 \times 10^{-5} \mathrm{mM}\right)$ in methanol were added into the test tubes and evaporated under a stream of nitrogen gas to remove the methanol. A serial of FACC solutions with different concentrations ranging from 2 to $250 \mu \mathrm{g} / \mathrm{ml}$ were prepared and then left to equilibrate with a constant pyrene concentration of 60 $\mathrm{nM}$ for $24 \mathrm{~h}$ at $37^{\circ} \mathrm{C}$. Fluorescence excitation spectra were measured at the excitation wavelength of $337 \mathrm{~nm}$, and the emission wavelength was $350 \mathrm{~nm}-450 \mathrm{~nm}$ for emission spectra. Both excitation and emission bandwidths were set at $8 \mathrm{~nm}$. The peak height intensity ratio (I384/I372) of the third peak I384 to the first peak I372 was plotted against the logarithm of polymer concentration. The intersection of the tangent to the curve at the inflection with the horizontal tangent through the points at low polymer concentrations was taken as the $\mathrm{CMC}$ value. 


\section{Preparation of PTX loaded FACC micelles}

PTX loaded micelles were prepared with FACC by a dialysis method. Briefly, $10 \mathrm{mg}$ FACC was dissolved in $5 \mathrm{ml}$ of HCl-THF mixture consisted of $100 \mathrm{mM}$ hydrochloric acid $(\mathrm{HCl})$ and tetrahydrofuran (THF) $(1: 1$, $\mathrm{v} / \mathrm{v}$ ) to make a FACC solution. Various concentrations of PTX were dissolved in methanol and added into FACC solution then sonicated with ultrasonic cleaner in $25^{\circ} \mathrm{C}$ water bath for $30 \mathrm{~min}$ with the power output of $200 \mathrm{~W}$. The blend solution $(5 \mathrm{ml})$ was dialyzed against $500 \mathrm{ml}$ de-ionized water and changed water every $2 \mathrm{~h}$ using a dialysis bag (cut-off MWCO $7 \mathrm{kDa}$ ). Followed that, the PTX-FACC micelles were obtained by lyophilization and kept for further analysis.

\section{Characterization of PTX-FACC micelles}

The particle sizes and polydispersities of PTXFACC micelles diluted in de-ionized water were determined using dynamic light scattering system Zetasizer Nano ZS90 (Malvern Instruments, UK) in triplicate.

PTX-FACC micelles $(1 \mathrm{mg})$ were dissolved with 1 $\mathrm{ml}$ of de-ionized water to make a testing sample. Onedrop sample was placed on a carbon-coated film 300 mesh copper grid and allowed to sit for $5 \mathrm{~min}$ or until air-dried. The sample was stained with uranyl acetate $(1 \%, \mathrm{~W} / \mathrm{V})$ for 5 min, and any excess uranyl acetate was removed with filter paper. Morphological characteristics of the micelles were examined using a high-resolution transmission electron microscope (TEM; JEM-2000EX, JEOL Co. Japan).

The encapsulation efficiency (EE) and loading efficiency (LE) of PTX-FACC micelles were determined by the high-performance liquid chromatography (HPLC, UV-230 II, Yilite, Dalian, China) assay described as follows: PTX-FACC micelles (1 mg) were dissolved in 2 $\mathrm{ml}$ of methanol and water mixture $(80: 20, \mathrm{v} / \mathrm{v})$, vortexed, then sonicated for $30 \mathrm{~min}$. The PTX concentrations were analyzed by HypersilODS- $\mathrm{C}_{18}$ column $(250 \mathrm{~mm} \times 4.6 \mathrm{~mm}$, $5 \mu \mathrm{m})$ using methanol : water $(80: 20, \mathrm{v} / \mathrm{v})$ as a mobile phase, the PTX was detected at the wavelength of 227 $\mathrm{nm}$, the flow rate was $1.0 \mathrm{~mL} / \mathrm{min}$ and the column was kept at $25^{\circ} \mathrm{C}$. EE and LE were calculated by the following equations:

$\mathrm{EE} \%=[$ weight of encapsulated drug/ weight of total drug] $\times 100 \%$

$\mathrm{LE} \%=$ [weight of encapsulated drug/ weight of total drug and vector] $\times 100 \%$

\section{In vitro release of $\mathrm{PTX}-\mathrm{FACC}$ micelles}

The in vitro release behavior of PTX from PTXFACC micelles were determined by dialysis method for up to 7 days. Each $50 \mathrm{mg}$ PTX-FACC micelles (contains $5 \mathrm{mg}$ PTX) were resuspended in $5 \mathrm{ml}$ de-ionized water.
This PTX-FACC micelle solution was dialyzed using a membrane dialysis bag $(1 \mathrm{ml} / \mathrm{bag}$; cut-off MWCO $7 \mathrm{kDa})$ in $50 \mathrm{ml} \mathrm{PBS}$ at $\mathrm{pH} 5.0,7.4$ and 9.0 at $37 \pm 0.5^{\circ} \mathrm{C}$ with continuous stirring for 7 days, respectively. To meet the sink condition, $0.5 \mathrm{ml}$ of polysorbate 80 was included in $50 \mathrm{ml}$ of releasing medium as a solubilizer $(1 \%$, $\mathrm{v} / \mathrm{v})$. An anticancer drug, Taxol ${ }^{\circledR}(1 \mathrm{ml}$ of $1 \mathrm{mgPTX})$ was also dialyzed in $50 \mathrm{ml}$ PBS at pH 7.4 and used as control labeled PTX. At each predetermined time point, $2 \mathrm{ml}$ releasing medium was taken, refilled with the same amount of the fresh medium. The concentration of the released PTX was determined by HPLC as described in the "Determination of encapsulation efficiency" section.

\section{Cytotoxicity assay}

The cytotoxicity of PTX-FACC micelles on two type cells was tested by MTT method. Briefly, Hela (folate receptor-positive) and A549 (folate receptor-negative) cells were seeded at a density of $1 \times 10^{4} /$ well in $100 \mu \mathrm{l}$ of medium in a 96-well culture plate and incubated for $24 \mathrm{hrs}$ at $37^{\circ} \mathrm{C}$. Different concentrations $(0.1,1,10,100 \mu \mathrm{g} / \mathrm{ml})$ of PTX-FACC micelles and Taxol ${ }^{\circledR}$ were added to the cells and incubated for another $24 \mathrm{hrs}$ at $37^{\circ} \mathrm{C}$, respectively. Discard the culture medium and then wash the plate with PBS. MTT solution $(0.5 \%, 10 \mu \mathrm{l})$ was added to the cells in each well and incubated for another $4 \mathrm{hrs}$ at $37^{\circ} \mathrm{C}$. Remove the culture medium, wash the plate with PBS and then added into $200 \mu \mathrm{l}$ DMSO. The culture plate was incubated for $30 \mathrm{~min}$ at $37^{\circ} \mathrm{C}$. Absorbance was detected on a Microplate Reader (Thermo Multiskan Ascent 354, USA) at $492 \mathrm{~nm}$. The cell viability was calculated as the following formula: Viable cells $\%=(\mathrm{OD}$ of treated group $/$ OD of control group) $\times 100 \%$. Different concentrations ( 1 , $5,10,50,100,500 \mu \mathrm{g} / \mathrm{ml}$ ) of FACC micelles were added to the two cells lines and treated as mentioned above.

\section{Intracellular uptake of PTX-FACC micelles}

In order to test the distribution of FACC micelles in Hela and A549 cells, FITC-conjugated FACC micelles were created according to the published protocol [28]. Hela and A549 cells were seeded at a density of $5 \times 10^{5} /$ well in a 6-well plate and incubated for $24 \mathrm{hrs}$ at $37^{\circ} \mathrm{C}$. Then $20 \mu \mathrm{l}$ of FITC-FACC micelles were added into each well and FITC solution only was used as control. After $2 \mathrm{~h}$ of incubation, all wells were incubated with rabbit monoclonal anti-human folate receptor (1:500) antibody for another $2 \mathrm{hrs}$ at $37^{\circ} \mathrm{C}$, followed by incubation with TRITC-labeled goat anti-rabbit immunoglobulin antibody (1:150) for $20 \mathrm{~min}$. All wells were washed three times with PBS, and nucleus was stained for 10 min with Hoechst $(50 \mu \mathrm{g} / \mathrm{ml})$. The staining solution was removed and washed three times with PBS. The fluorescence in each sample was monitored by a SP5 laser scanning confocal microscopy (Germany). 


\section{Statistical analysis}

All experiments were repeated at least three times and the data were presented as the mean \pm standard deviation (SD). Tukey's test was performed to determine statistical significance and a $P$ value $<0.05$ was considered to be significantly different.

\section{CONCLUSION}

The novel amphiphilic folate acid-cholesterolchitosan nanoscale micelles were prepared to the targeted delivery of paclitaxel. The PTX-FACC micelles developed in this study had suitable diameter, high encapsulation efficiency and loading capacity, uniform spherical morphology, and slow release in vitro. In addition, in vitro cytotoxicity assays confirmed that PTX-FACC micelles have a higher cytotoxicity than the Taxol®. PTX-FACC micelles may provide a potential tool to target FR-positive cancer cells and hence is a promising candidate for anticancer activity.

\section{ACKNOWLEDGMENTS}

This work was funded by the Science and Technology Planning Project of Dalian, China (No. 2014E14SF184).

\section{CONFLICTS OF INTEREST}

The authors declare no conflicts of interest.

\section{REFERENCES}

1. Saadat E, Amini M, Khoshayand MR, Dinarvand R, Dorkoosh FA. Synthesis and optimization of a novel polymeric micelle based on hyaluronic acid and phospholipids for delivery of paclitaxel, in vitro and in-vivo evaluation. Int J Pharm. 2014; 475: 163-73. doi: 10.1016/j. ijpharm.2014.08.030.

2. Koo H, Min KH, Lee SC, Park JH, Park K, Jeong SY, Choi K, Kwon IC, Kim K. Enhanced drug-loading and therapeutic efficacy of hydrotropic oligomer-conjugated glycol chitosan nanoparticles for tumor-targeted paclitaxel delivery. J Control Release. 2013; 172: 823-31. doi: 10.1016/j.jconrel.2013.08.297.

3. Chen MX, Li BK, Yin DK, Liang J, Li SS, Peng DY. Layerby-layer assembly of chitosan stabilized multilayered liposomes for paclitaxel delivery. Carbohydr Polym. 2014; 111: 298-304. doi: 10.1016/j.carbpol.2014.04.038.

4. Madrigal-Carballo S, Vila AO, Sibaja M, Reed JD, Molina F. In vitro uptake of lysozyme-loaded liposomes coated with chitosan biopolymer as model immunoadjuvants. J Liposome Res. 2010; 20: 1-8. doi: 10.3109/08982100903015009.
5. Yu DH, Lu Q, Xie J, Fang C, Chen HZ. Peptide-conjugated biodegradable nanoparticles as a carrier to target paclitaxel to tumor neovasculature. Biomaterials. 2010; 31: 2278-92. doi: 10.1016/j.biomaterials.2009.11.047.

6. Chakravarthi SS, Robinson DH. Enhanced cellular association of paclitaxel delivered in chitosan-PLGA particles. Int J Pharm. 2011; 409: 111-20. doi: 10.1016/j. ijpharm.2011.02.034.

7. Vert M, Mauduit J, Li S. Biodegradation of PLA/GA polymers: increasing complexity. Biomaterials. 1994; 15: 1209-13.

8. Godsey ME, Suryaprakash S, Leong KW. Materials innovation for co-delivery of diverse therapeutic cargos. RSC Adv. 2013; 3: 24794-811. doi: 10.1039/C3RA43094D.

9. Woraphatphadung T, Sajomsang W, Gonil P, Treetong A, Akkaramongkolporn P, Ngawhirunpat T, Opanasopit P. $\mathrm{pH}$-Responsive polymeric micelles based on amphiphilic chitosan derivatives: Effect of hydrophobic cores on oral meloxicam delivery. Int J Pharm. 2016; 497: 150-60. doi: 10.1016/j.ijpharm.2015.12.009.

10. Duhem N, Rolland J, Riva R, Guillet P, Schumers JM, Jerome C, Gohy JF, Preat V. Tocol modified glycol chitosan for the oral delivery of poorly soluble drugs. Int J Pharm. 2012; 423: 452-60. doi: 10.1016/j. ijpharm.2011.12.010.

11. Zhou H, Liu X, Guo X, Li N, Yu W, Zhang Y, Ma X. Synthesis and characterization of amphiphilic chitosan derivatives as a nano-carrier for paclitaxel delivery. J Control Release. 2011; 152: e124-5. doi: 10.1016/j. jconrel.2011.08.166.

12. Yuan ZQ, Li JZ, Liu Y, Chen WL, Yang SD, Zhang CG, Zhu WJ, Zhou XF, Liu C, Zhang XN. Systemic delivery of micelles loading with paclitaxel using N-succinylpalmitoyl-chitosan decorated with cRGDyK peptide to inhibit non-small-cell lung cancer. Int J Pharm. 2015; 492: 141-51. doi: 10.1016/j.ijpharm.2015.07.022.

13. Li H, Liu J, Ding S, Zhang C, Shen W, You Q. Synthesis of novel $\mathrm{pH}$-sensitive chitosan graft copolymers and micellar solubilization of paclitaxel. Int J Biol Macromol. 2009; 44: 249-56. doi: 10.1016/j.ijbiomac.2008.12.011.

14. Wang X, Chen Y, Dahmani FZ, Yin L, Zhou J, Yao J. Amphiphilic carboxymethyl chitosan-quercetin conjugate with P-gp inhibitory properties for oral delivery of paclitaxel. Biomaterials. 2014; 35: 7654-65. doi: 10.1016/j. biomaterials.2014.05.053.

15. Liang N, Sun S, Li X, Piao H, Piao H, Cui F, Fang L. alpha-Tocopherol succinate-modified chitosan as a micellar delivery system for paclitaxel: preparation, characterization and in vitro/in vivo evaluations. Int J Pharm. 2012; 423: 480-8. doi: 10.1016/j.ijpharm.2011.12.004.

16. Zhang Z, Jia J, Lai Y, Ma Y, Weng J, Sun L. Conjugating folic acid to gold nanoparticles through glutathione for targeting and detecting cancer cells. Bioorg Med Chem. 2010; 18: 5528-34. doi: 10.1016/j.bmc.2010.06.045. 
17. Rathinaraj P, Lee K, Park SY, Kang IK. Targeted images of $\mathrm{KB}$ cells using folate-conjugated gold nanoparticles. Nanoscale Res Lett. 2015; 10: 5. doi: 10.1186/ s11671-014-0725-y.

18. Du J, Lane LA, Nie S. Stimuli-responsive nanoparticles for targeting the tumor microenvironment. J Control Release. 2015; 219: 205-14. doi: 10.1016/j. jconrel.2015.08.050.

19. Nagpal K, Singh SK, Mishra DN. Chitosan nanoparticles: a promising system in novel drug delivery. Chem Pharm Bull (Tokyo). 2010; 58: 1423-30.

20. Yinsong W, Lingrong L, Jian W, Zhang Q. Preparation and characterization of self-aggregated nanoparticles of cholesterol-modified O-carboxymethyl chitosan conjugates. Carbohydrate Polymers. 2007; 69: 597-606. doi: 10.1016/j. carbpol.2007.01.016.

21. Tan YL, Liu CG. Preparation and characterization of selfassembled nanoparticles based on folic acid modified carboxymethyl chitosan. J Mater Sci Mater Med. 2011; 22: 1213-20. doi: 10.1007/s10856-011-4302-y.

22. Hansson A, Hashom N, Falson F, Rousselle P, Jordan O, Borchard G. In vitro evaluation of an RGD-functionalized chitosan derivative for enhanced cell adhesion. Carbohydr Polym. 2012; 90: 1494-500. doi: 10.1016/j. carbpol.2012.07.020.
23. Mansouri S, Cuie Y, Winnik F, Shi Q, Lavigne P, Benderdour M, Beaumont E, Fernandes JC. Characterization of folatechitosan-DNA nanoparticles for gene therapy. Biomaterials. 2006; 27: 2060-5. doi: 10.1016/j.biomaterials.2005.09.020.

24. Yu J, Xie X, Wu J, Liu Y, Liu P, Xu X, Yu H, Lu L, Che X. Folic acid conjugated glycol chitosan micelles for targeted delivery of doxorubicin: preparation and preliminary evaluation in vitro. J Biomater Sci Polym Ed. 2013; 24: 606-20. doi: 10.1080/09205063.2012.701548.

25. Liu J, Li H, Jiang X, Zhang C, Ping Q. Novel pH-sensitive chitosan-derived micelles loaded with paclitaxel. Carbohydrate Polymers. 2010; 82: 432-9. doi: 10.1016/j. carbpol.2010.04.084.

26. Ma Y, Fan X, Li L. pH-sensitive polymeric micelles formed by doxorubicin conjugated prodrugs for co-delivery of doxorubicin and paclitaxel. Carbohydr Polym. 2016; 137: 19-29. doi: 10.1016/j.carbpol.2015.10.050.

27. Prabaharan M. Chitosan-based nanoparticles for tumortargeted drug delivery. Int J Biol Macromol. 2015; 72: 1313-22. doi: 10.1016/j.ijbiomac.2014.10.052.

28. Hu FQ, Wu XL, Du YZ, You J, Yuan H. Cellular uptake and cytotoxicity of shell crosslinked stearic acidgrafted chitosan oligosaccharide micelles encapsulating doxorubicin. Eur J Pharm Biopharm. 2008; 69: 117-25. doi: 10.1016/j.ejpb.2007.09.018. 